\title{
The Chemical Composition and Functional Properties of Essential Oils from Four Species of Schisandra Growing Wild in the Qinling Mountains, China
}

\author{
Xiaorui Wang ${ }^{1,2,3}$, Yan Liu ${ }^{2,3}$, Yuanyuan Niu ${ }^{2,3}$, Nongxue Wang ${ }^{2,3}$ and Wei Gu ${ }^{1,2,3, *}$ \\ 1 National Engineering Laboratory for Resource Development of Endangered Crude Drugs in Northwest of \\ China, College of Life Sciences, Shaanxi Normal University, Xi'an 710119, China; wangxiaorui@snnu.edu.cn \\ 2 The Key Laboratory of Medicinal Resources and Natural Pharmaceutical Chemistry, The Ministry \\ of Education, College of Life Sciences, Shaanxi Normal University, Xi'an 710119, China; \\ liuyan68@snnu.edu.cn (Y.L.); n201706016@snnu.edu.cn (Y.N.); wangnongxue@snnu.edu.cn (N.W.) \\ 3 College of Life Sciences, Shaanxi Normal University, Xi'an 710119, China \\ * Correspondence: weigu@snnu.edu.cn; Tel.: +86-029-85310266; Fax: +86-029-85310546
}

Received: 8 June 2018; Accepted: 30 June 2018; Published: 5 July 2018

\begin{abstract}
The aim of this study was to investigate the chemical composition and functional properties of the essential oils from the plants Schisandra grandiflora (Wall.) Hook. f. et Thoms, Schisandra rubriflora (Franch). Rehd. et Wils., Schisandra sphenanthera Rehd. et Wils., and Schisandra propinqua (Wall.) Baill var. sinensis Oliv. collected in the Qinling Mountains. Under the optimum conditions of the ultrasonic-assisted extraction method, the extraction yields were $7.51 \%$ (S. grandiflora), $6.91 \%$ (S. rubriflora), $6.11 \%$ (S. sphenanthera), and $5.88 \%$ (S. propinqua). A total of 86 components were identified from four species of Schisandra and 16 components were shared among the essential oils of all samples with different contents. However, some components were identified only in a certain plant, for example, $\beta$-caryophyllen (S. grandiflora), $\alpha$-bulnesene (S. rubriflora), and $\alpha$-Chamigrene (S. propinqua). Terpenoids (sesquiterpenes and oxygenated sesquiterpenes), accounting for $73.87-82.08 \%$ of the total compounds, were the main components. Meanwhile, the antioxidant activities of the essential oils were evaluated through three free radical scavenging assays and a reducing power assay, which were related to the contents of the individual bioactive composition. These results provide a phytochemical foundation for the use of four species, and for the further study of the identification of Schisandra species.
\end{abstract}

Keywords: Schisandra; essential oils; ultrasonic-assisted extraction; antioxidant activity

\section{Introduction}

The genus Schisandra comprises about 30 species of woody and deciduous liana and is widely distributed over Southeastern and Central China [1-3]. The fresh fruits of Schisandra species can be steeped in wine or eaten directly. Most Schisandra species are medicinal plants and their dry fruits are widely used as local traditional medicines; however, only two species, Schisandra sphenanthera Rehd. et Wils. (SS) and Schisandra chinensis (Turcz.) Baill., have been officially listed in the Chinese Pharmacopoeia for the treatment of coughs and asthma, palpitations and insomnia, night sweats, liver injury and so on, and have also been attributed antiviral and anticancer activity [4,5]. As the genuine origin of $S S$, the Qinling Mountains have a wealth of $S S$ resources that are high quality and in a wide growing area [6,7]. In comparison, other Schisandra species gave attracted little attention because of their limited growing area and narrow range of application. Schisandra grandiflora (Wall.) Hook. f. et Thoms. (SG), Schisandra rubriflora (Franch). Rehd. et Wils. (SR) and Schisandra propinqua 
(Wall.) Baill. var. sinensis Oliv. (SP) are the three species of Schisandra that mainly grown in the Qinling Mountains [8]. They were used as herbal medicines against HIV [9,10] and many other diseases [11].

Lignans are considered to be the pharmacologically active components of Schisandra species and it many kinds of lignans have been isolated from this genus, such as dibenzocyclooctadiene, dibenzylbutane, and tetrahedrofurane [12,13]. However, up until now, little attention has been paid to the essential oils of four species of Schisandra and the antioxidant activity of essential oils. Essential oils are complex mixtures of terpenoids, aromatics, esters, alcohols, and ketones obtained from plant material. The analysis of essential oils is a significant and growing area, as the components of essential oils present in plant materials are increasingly recognized to possess aromatic, antibacterial, insecticidal, and biological properties [14-17].

The present study was performed to investigate the components of essential oils from four species of Schisandra growing in the Qinling Mountains, as well as to understand their antioxidant activities, which were evaluated through the three free radical scavenging assays and the reducing power assay, and this study could provide useful information for the further study of the four medicinal species.

\section{Results and Discussion}

\subsection{Optimization of the Extraction Yield}

It is well known that various parameters play an important role in the optimization of the experimental conditions for the development of the ultrasonic-assisted extraction method. Raw material to solvent ratio, ultrasonic time, ultrasonic temperature, and ultrasonic power are generally considered to be the most important factors that affect the yield (\%) of essential oils. Figure 1 shows the experimental results of the single-factor experiment, which is applied to better understand the effects of parameters. As shown in the graph, ultrasonic power and the raw material to solvent ratio were the most significant parameters.

Four independent variables with three variation levels are listed in Table S1. Table S2 shows the experimental conditions and extraction yields for each test. The highest extraction yield was obtained in test 8 at a 1:10 ratio, $30 \mathrm{~min}, 30^{\circ} \mathrm{C}$, and $240 \mathrm{~W}$. As laid out in the table below, the extraction yields were significantly different when we changed the operating conditions. According to the results of the analysis of variance table (Table S3), we found that the effect of ultrasonic power on essential oils extracted from $S S$ was extremely significant but the effects of the other factors were not significant. The factors influenced the yield (\%) of essential oils in the following order: ultrasonic power $>$ ultrasonic temperature $>$ ultrasonic time $>$ ratio of material to solvent. In confirmation tests, the content of essential oils extracted from SS by the optimum extracting technology reached $6.07 \%$, which was the average value of the triplicate experiments.
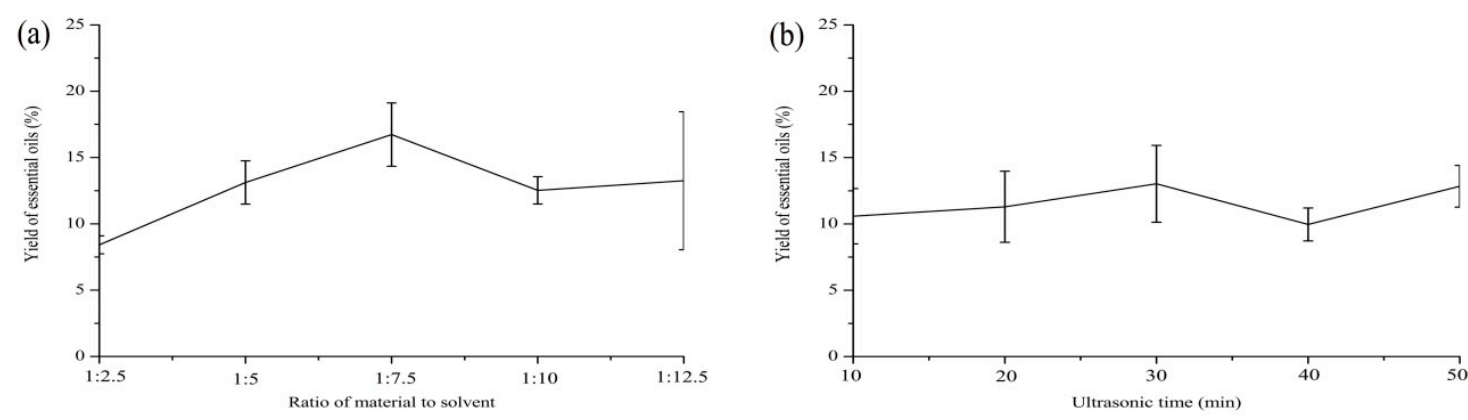

Figure 1. Cont. 

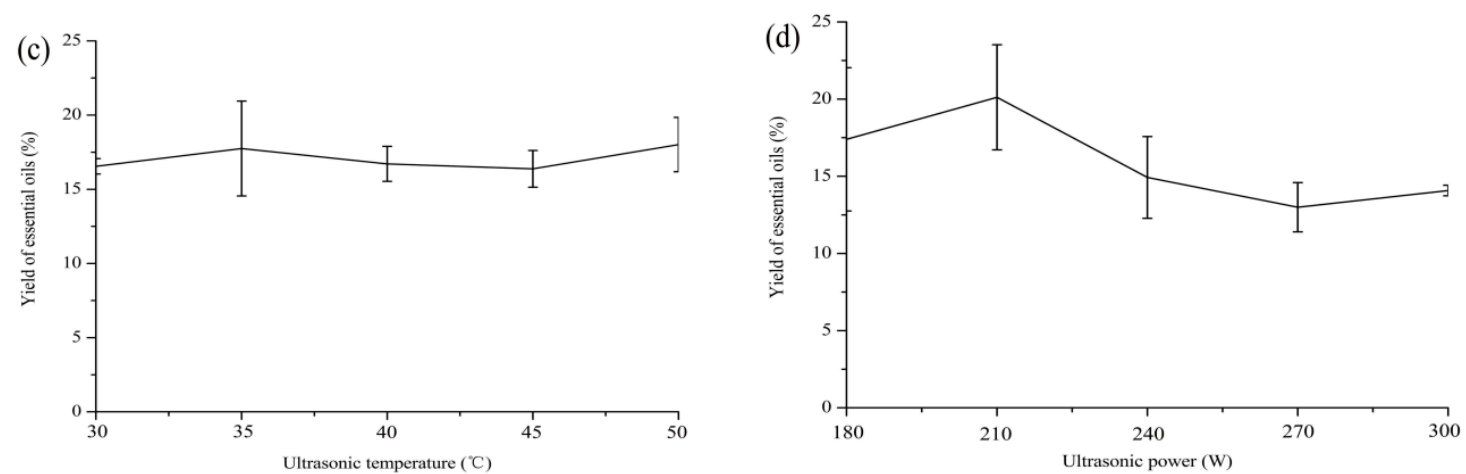

Figure 1. Effect of different parameters on the extraction yield of essential oils from S. sphenanthera: (a) ratio of material to solvent; (b) ultrasonic time; (c) ultrasonic temperature; (d) ultrasonic power.

\subsection{Yield of Essential Oil}

In this study, we examined the colors and yields $(\% v / w)$ of essential oils from the fruits of four species of Schisandra. All the samples studied were fragrant and had different colors: milk white for $S P$, yellow for $S S$, saffron yellow for $S G$, and wheat for $S R$. The yield of fruit essential oil ranged from $5.88 \%$ to $7.51 \%(v / w)$. The highest yield of essential oils was $S G(7.51 \%)$, followed by $S R(6.91 \%)$, SS $(6.11 \%)$, and SP $(5.88 \%)$. The yields of essential oils from the fruits of four species far exceeded the yield of the essential oils from the fruits of SS obtained from hydrodistillation [18].

The essential oils, which were extracted from aromatic plants, had a wide range of medicinal and industrial applications [19]. According to our literature survey, many factors influenced the yields of essential oils, such as harvest time [20], developmental stage [21], different parts [22,23], and environmental conditions [24]. To reduce the influences of the factors in the present study, we selected the same parts (fruits) of Schisandra species, and sampled them at the same time. Consequently, the influences of different parts, harvesting time, and technical parameters were considered negligible. In our study, the three wild Schisandra species (SS, SG, and SR) were sampled in Taibai, grown in the same environmental conditions, and SP were sampled in Pingli (Table 1). The differences in the yield and composition of essential oils could mainly be attributed to the genotypes of different species of Schisandra, but for $S P$, we also need to consider the effect of the environment.

\subsection{Essential Oils Composition}

Figure 2 shows a comparative chromatogram of essential oils from the fruits of four species of Schisandra, and detailed components are compared in Table S4. The components of essential oils from all samples with low content $(<0.1 \%)$ are not listed in Table S4. A total of 86 components were identified from all samples, and 16 components were shared among the essential oils of Schisandra species, with different contents. The major shared components of essential oils from four species belonged to the sesquiterpenes and oxygenated sesquiterpenes, such as $\beta$-himachalene and $\alpha$-bisabolol. However, some components were identified only in a certain plant (Table 2). For example, $\beta$-caryophyllene was a characteristic component of $S G$. $\alpha$-Bulnesene was only found in $S R$. Longiverbenone was only identified in $S S$ and $\alpha$-chamigrene only in $S P$.

Table 1. A summary of the tested samples.

\begin{tabular}{cccccc}
\hline Sample Name & Sources & Elevation $\mathbf{( k m )}$ & Longitude & Latitude & Acquisition Time \\
\hline S. grandiflora & Taibai, Baoji, Shaanxi & 2.03 & $107^{\circ} 30.576^{\prime}$ & $34^{\circ} 01.330^{\prime}$ & September 2013 \\
S. rubriflora & Taibai, Baoji, Shaanxi & 1.95 & $107^{\circ} 17.705^{\prime}$ & $33^{\circ} 59.836^{\prime}$ & September 2013 \\
S. sphenanthera & Taibai, Baoji, Shaanxi & 1.23 & $106^{\circ} 36.396^{\prime}$ & $32^{\circ} 50.795^{\prime}$ & September 2013 \\
S. propinqua & Pingli, Ankang, Shaanxi & 0.60 & $109^{\circ} 18.392^{\prime}$ & $32^{\circ} 23.350^{\prime}$ & September 2013 \\
\hline
\end{tabular}


(a)

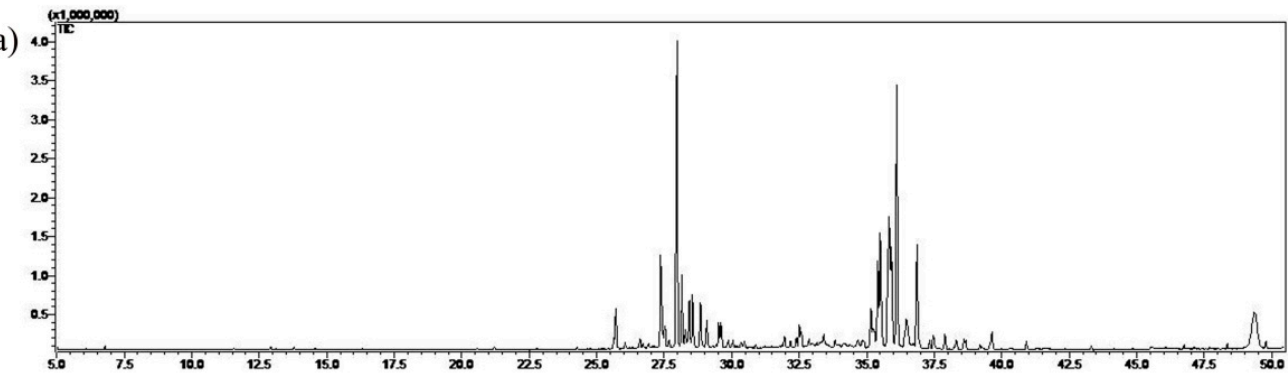

(b) 10

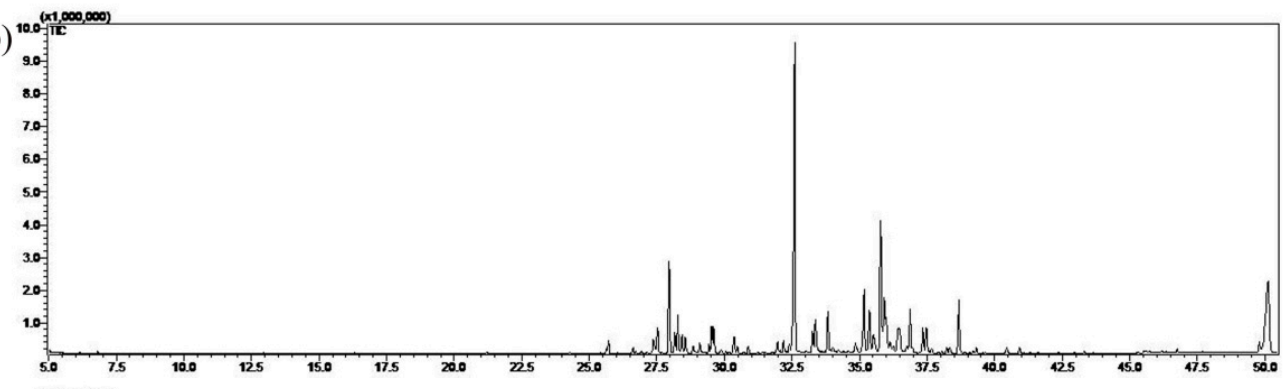

(c)

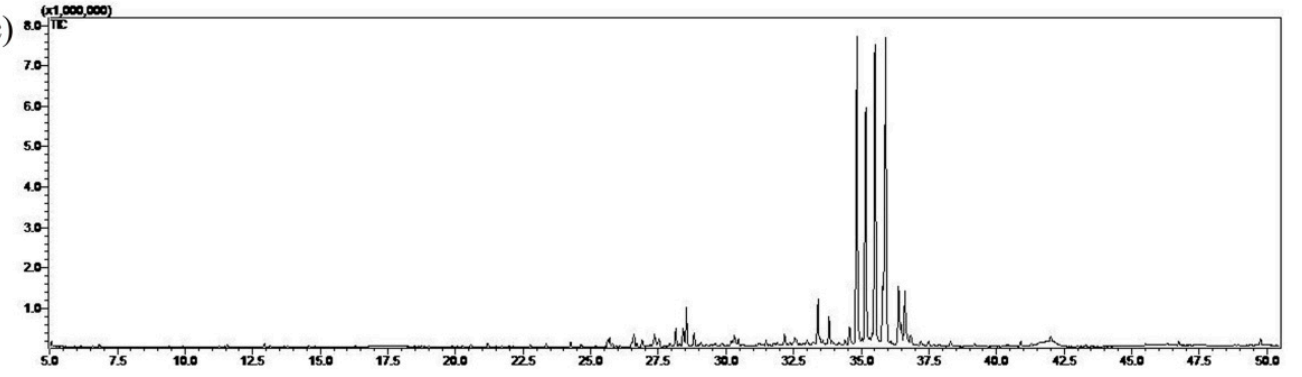

(d)

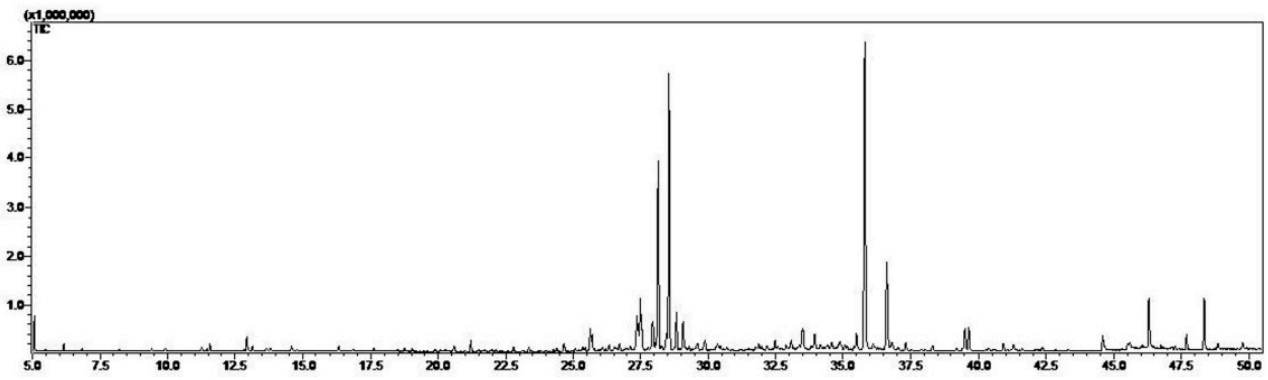

Figure 2. The total ion chromatograms of four species ((a) SG; (b) SR; (c) SS; (d) SP) in Schisandra under GC-MS.

To evaluate the biodiversity of the essential oils in the four species, the identified components were classified by their chemical structure with the help of literature data and reference components [25]. In Table S4, we list six chemical groups of components in the essential oils from four species of Schisandra. The four species had similar chemical groups: sesquiterpenes and oxygenated sesquiterpenes were the principal components, accounting for $30.43-59.64 \%$ and $15.82-51.65 \%$, respectively. However, there were many differences in the kinds and numbers of components between the two groups. This situation was caused by the stable genotypes and different levels of gene expression of Schisandra species. The results of our study were consistent with previous studies in that sesquiterpenes and oxygenated sesquiterpenes were major chemical groups in the Schisandra extracts [26,27].

In this study, the essential oils extracted from the fruits of four species had some identical components to those reported previously in the literature. For instance, $\delta$-cadinene, $\beta$-chamigrene, and $\gamma$-muurolene were also found in SS purchased from Shanghai Pharmacy Co., Ltd., Shanghai, China [18]. $\alpha$-Muurolene, caryophyllene, and $\gamma$-elemene were also the major components in $S P$ purchased from Chinese medicine market, Zunyi, Guizhou, China [28]. However, in previous studies, 
research into the essential oils in $S G$ and $S R$ was not mentioned, and our study is the first to research the essential oils of two of the species.

Table 2. The particular components of sesquiterpenes and oxygenated sesquiterpenes of four species of Schisandra.

\begin{tabular}{ccc}
\hline Species & Compound Name & $\mathbf{R C}^{\mathbf{b}} \mathbf{( \% )} \pm \mathbf{S D}$ \\
\hline \multirow{4}{*}{$S G$} & $\beta$-Sesquiphellandrene & $1.33 \pm 0.43$ \\
& $\beta$-Caryophyllene & $3.52 \pm 0.31$ \\
& Isocaryophyllene & $12.50 \pm 4.36$ \\
& $\alpha$-Guaiene & $4.51 \pm 0.22$ \\
D-nerolidol & $1.45 \pm 0.19$ \\
& Epiglobulol & $1.91 \pm 1.57$ \\
\hline \multirow{4}{*}{$S R$} & $\delta$-Elemene & $2.13 \pm 1.10$ \\
& $\alpha$-Caryophyllene & $0.34 \pm 0.05$ \\
& $\alpha$-Ylangene & $1.14 \pm 0.03$ \\
& 4,5-dehydro- Isolongifolene & $3.73 \pm 0.08$ \\
& $\alpha$-Bulnesene & $2.71 \pm 0.71$ \\
& $\alpha$-Farnesene & $1.31 \pm 0.19$ \\
& Humulane-1,6-dien-3-ol & $0.93 \pm 0.03$ \\
MS & Euurolol & $0.64 \pm 0.05$ \\
& Elemol & $15.08 \pm 0.20$ \\
\hline \multirow{4}{*}{$S P$} & Cadinene & $0.38 \pm 0.08$ \\
& Germacrene D-4-ol & $2.45 \pm 0.13$ \\
& Cedrenol & $0.68 \pm 0.20$ \\
& Longiverbenone & $10.43 \pm 1.06$ \\
\hline
\end{tabular}

Note SD: standard deviation; b: Relative composition.

The biological activities of the essential oils are related to the major components. For the essential oils of $S G$, isocaryophyllene and ylangene were the dominant components. Ylangene showed significant inhibitory activities against protein-tyrosine phosphatase 1B [29]. Isocaryophyllene was the precursor of $\beta$-caryophyllene, which was known for its anti-inflammatory, local anesthetic, and repellent activity against the adult form of Lasioderma serricorne [30,31]. Elemol was the major component of $S R$, and as a fragrance ingredient it was used in cosmetics, fine fragrances, shampoos, toilet soaps, and other toiletries as well as in non-cosmetic products [32]. There were three more prominent components of essential oils from the fruits of SS. Isospathulenol was the isomer of spathulenol, which had an immune-inhibitory effect on activated lymphocytes [33], longiverbenone was classified as an active toxic compound [34], and the use of cedrenol had similar effects to that of elemol [35]. However, the functions of the dominant components of $S P$ were various: $\alpha$-muurolene was the enantiomer of $(+)-\delta$-cadinene, which played an important role in the biosynthesis of gossypol [36], and caryophyllene was a metabolite of both plants and fungi, and was also biologically active as an immunosuppressive, cytotoxic, antibacterial, and antifungal agent [37].

\subsection{Antioxidant Activities of Essential Oils}

Antioxidant activity is a complex process and is the sum of several mechanisms, such as free radical scavenging and reducing capacity [38]. In Figure 3, the essential oils from all four species of Schisandra presented high free radical scavenging and low reducing capacity. There were significant differences among the free radical scavenging activities of four species, while it was kept at a constant level with a continuous increase in concentration, and their $50 \%$ scavenging capacity $\left(\mathrm{EC}_{50}\right)$ values are listed in Table 3. VC and VE were the positive control.

The scavenging capacities of the essential oils from all samples on DPPH radical were much lower than VC, which achieved a maximum value of $93 \%$ when the concentration increased to $100 \mu \mathrm{g} / \mathrm{mL}$. The capacity of scavenging activity on superoxide anion free radical was in the same descending order $\left(\mathrm{EC}_{50}\right): \mathrm{VC}>S P>S G \approx S R>S S>\mathrm{VE}$, different from the results of the DPPH radical scavenging assay. Moreover, the capacity of scavenging activity on hydroxyl free radical was in the same descending order $\left(\mathrm{EC}_{50}\right): \mathrm{VC}>S R>S G>\mathrm{VE}>S S>S P$. 
Table 3. The results for free radical scavenging of four species.

\begin{tabular}{|c|c|c|c|}
\hline Oxidant & Sample & Regression Equation & $\mathrm{EC}_{50}(\mathrm{mg} / \mathrm{mL}) \pm \mathrm{SD}$ \\
\hline \multirow{6}{*}{$\mathrm{DPPH}$} & $\mathrm{VC}$ & $y=92.180-82.651 / x$ & $1.960 \times 10^{-3} \pm 0.060$ \\
\hline & VE & $y=0.018 x^{3}-0.707 x^{2}+10.178 x+17.532$ & $4.368 \pm 0.052$ \\
\hline & $S G$ & $y=0.029 x^{3}-1.281 x^{2}+17.646 x+15.944$ & $2.291 \pm 0.036$ \\
\hline & $S R$ & $y=0.082 x^{3}-2.710 x^{2}+24.830 x+24.684$ & $1.162 \pm 0.054$ \\
\hline & SS & $y=0.099 x^{3}-3.242 x^{2}+28.974 x+20.162$ & $1.180 \pm 0.013$ \\
\hline & $S P$ & $y=0.074 x^{3}-2.569 x^{2}+25.514 x+12.019$ & $1.797 \pm 0.023$ \\
\hline \multirow{6}{*}{ Superoxide anion } & $\mathrm{VC}$ & $y=-0.002 x^{2}+0.741 x+6.553$ & $73.027 \times 10^{-3} \pm 2.036$ \\
\hline & VE & $y=0.002 x^{3}-0.141 x^{2}+3.430 x+0.716$ & $44.362 \pm 3.046$ \\
\hline & $S G$ & $y=0.019 x^{3}-0.618 x^{2}+5.528 x+27.319$ & $21.625 \pm 2.233$ \\
\hline & $S R$ & $y=0.010 x^{3}-0.385 x^{2}+5.078 x+18.510$ & $21.860 \pm 3.215$ \\
\hline & SS & $y=-0.048 x^{2}+2.156 x+8.444$ & $25.510 \pm 2.357$ \\
\hline & $S P$ & $y=0.021 x^{3}-0.690 x^{2}+6.909 x+22.863$ & $19.257 \pm 3.456$ \\
\hline \multirow{6}{*}{ Hydroxyl radical } & $\mathrm{VC}$ & $y=-0.034 x^{2}+1.918 x+41.245$ & $5.009 \times 10^{-3} \pm 0.126$ \\
\hline & VE & $y=0.073 x^{3}-2.442 x^{2}+23.292 x+10.161$ & $2.174 \pm 0.079$ \\
\hline & $S G$ & $y=0.069 x^{3}-2.286 x^{2}+21.085 x+22.634$ & $1.544 \pm 0.043$ \\
\hline & $S R$ & $y=0.027 x^{3}-0.956 x^{2}+10.175 x+42.756$ & $0.766 \pm 0.032$ \\
\hline & SS & $y=0.021 x^{3}-0.851 x^{2}+11.812 x+26.461$ & $2.376 \pm 0.069$ \\
\hline & $S P$ & $y=0.007 x^{3}-0.438 x^{2}+8.533 x+18.063$ & $4.862 \pm 0.147$ \\
\hline
\end{tabular}

Note SD: standard deviation.
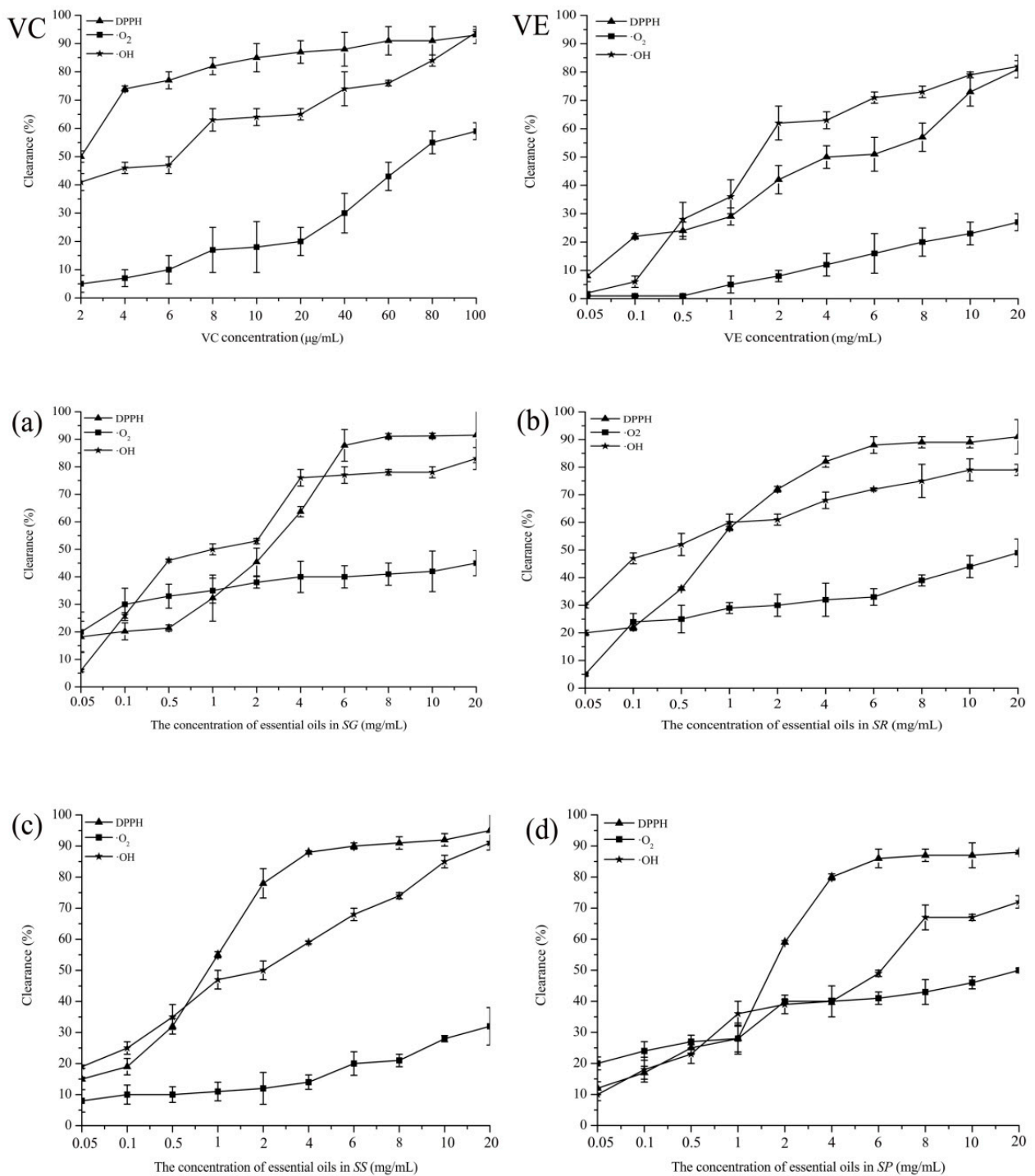

Figure 3. The results of free radical scavenging activities of essential oils from four species ((a) $S G$; (b) $S R$; (c) $S S$; (d) $S P$ ). 
The results of the reducing power assay of essential oils from the four species in comparison with VC and VE as the reference antioxidant are presented in Figure 4. The reducing ability increased with increasing oil concentrations and the value of absorbance revealed the reducing power. In Figure 4, the capacities of the reducing power of the essential oils were quite a bit lower than the reference antioxidant.

There were large differences in the free radical scavenging activity of the essential oils from four species of Schisandra (Table 3). The free radical scavenging activity of essential oils could be due to their higher content of sesquiterpenes and oxygenated sesquiterpenes components, which were isocaryophyllene, isospathulenol, $\alpha$-muurolene, and longiverbenone according to the GC-MS analysis (Table S4).
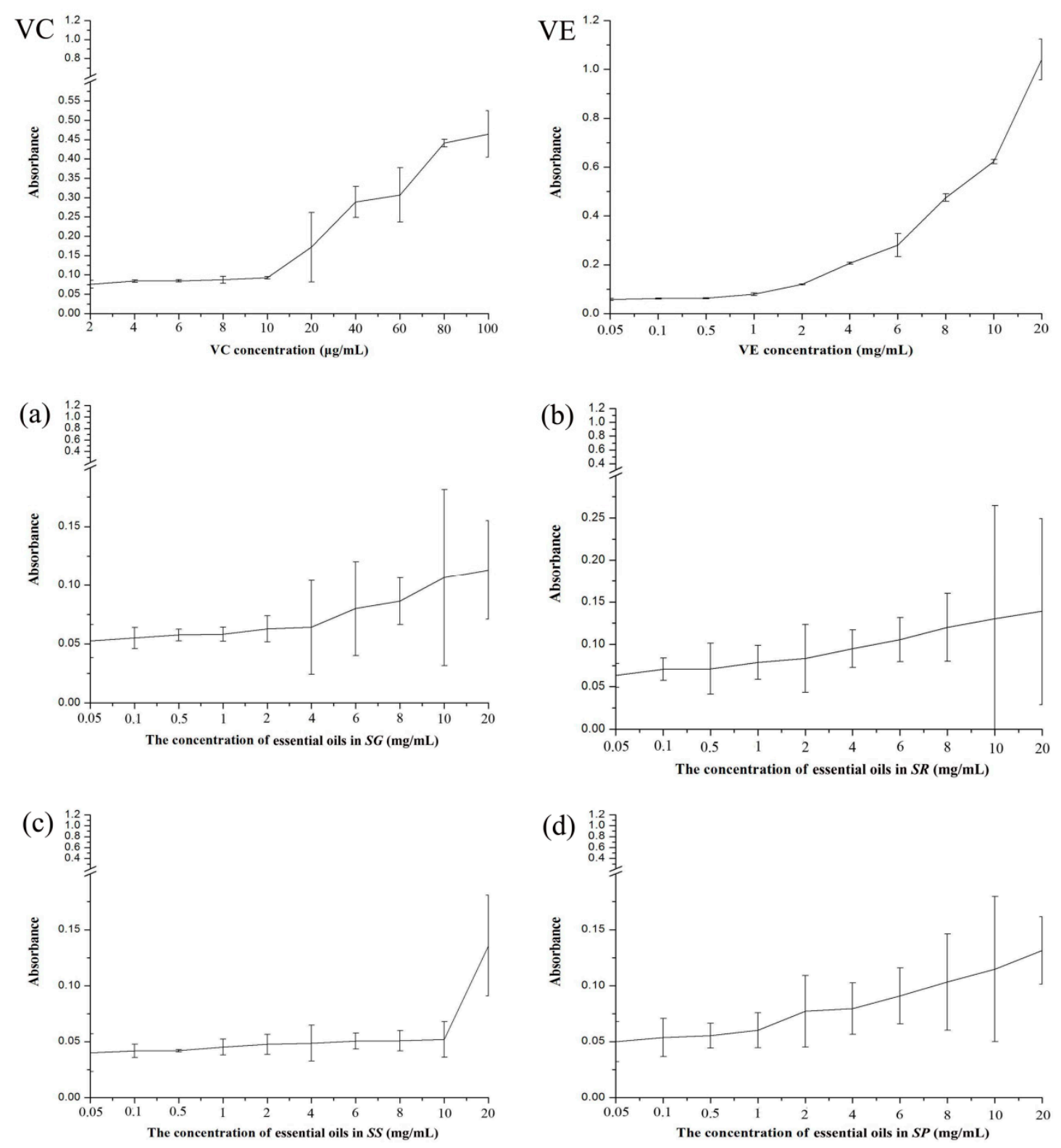

Figure 4. The results of reducing power assay of essential oils from four species ((a) $S G$; (b) $S R$; (c) $S S$; (d) $S P$ ). 


\section{Materials and Methods}

\subsection{Materials and the Extraction of Essential Oils}

Plant materials were collected from different regions of the Qinling Mountains (Table 1) and air-dried in the shade at room temperature. All of the samples were identified by Professor Yi Ren (Professor of Plant Taxonomy, Shaanxi Normal University) and a voucher specimen was kept in the College of Life Sciences, Shaanxi Normal University. Every species included at least 10 individuals as one sample. The fruits of all plant materials were comminuted to dried powders separately (screen size 40 meshes) in a pharmaceutical disintegrator, which was used for each extraction to determine the content of the essential oils. Each dried powder sample was extracted with petroleum ether at a designed time, temperature, power and raw material to solvent ratio through the ultrasonic-assisted extraction method $[39,40]$. The extraction solution was separated from the insoluble residue by centrifugation (1200 rpm for $3 \mathrm{~min}$ ) and then we collected the supernatant.

\subsection{Optimization of Essential Oil Extraction}

An orthogonal $\mathrm{L}_{9}(3)^{4}$ test design was used to investigate the optimal extraction conditions of essential oils from $S S$ and the extraction experiment was carried out with four factors and three levels in Table S1. The range of each factor level was based on the results of the single-factor experiments. The yield (\%) of essential oils from SS was the dependent variable, which was calculated as the content of essential oils divided by the dried pre-treated sample weight. Nine experiments were performed in order to estimate the best conditions for the extraction of essential oils, and it was repeated three times to avoid errors.

\subsection{Analytical Procedures (GC/MS)}

Analyses of essential oils were carried out on a Shimadzu (Japan) GC-MS-QP 2010 system using a chromatographic column, Rtx-5ms (30 m × $0.25 \mathrm{~mm}, 0.25 \mu \mathrm{m}$ film thickness, 5\% diphenyl—95\% dimethyl polysiloxane) $[41,42]$. The oven column temperature was programmed as follows: the initial temperature was $50^{\circ} \mathrm{C}$ for $2 \mathrm{~min}$, then increased at a rate of $4{ }^{\circ} \mathrm{C} / \mathrm{min}$ to $180{ }^{\circ} \mathrm{C}$ and held isothermally at $180{ }^{\circ} \mathrm{C}$ for $2 \mathrm{~min}$, and finally increased to $240{ }^{\circ} \mathrm{C}$ at a rate of $5{ }^{\circ} \mathrm{C} / \mathrm{min}$, which was maintained for $2 \mathrm{~min}$. Then, $1.0 \mu \mathrm{L}$ of the sample was injected at an injection port temperature of $230^{\circ} \mathrm{C}$. The ionizing voltage was $70 \mathrm{eV}$ and the mass spectra were obtained by automatic scanning at $m / z$ 35-550 amu.

\subsection{Composition Identification}

Through comparing the retention time (RT) and retention indices (RI) with the analysis done under the same temperature and the same chromatographic conditions, the essential oils from four species of Schisandra were preliminarily identified. Further identification of components was based on matching their recorded mass spectra with those from the NIST05.LIB and NIST05s.LIB library data (National Institute of Standards and Technology) provided by the software of GC-MS data systems [43]. The relative concentration of the components was calculated by comparing its GC peak area to the total area, were summed from all peaks that were detected $(\%)$.

\subsection{Analyses of Antioxidant Activities}

The free radical scavenging capacity of the essential oils was measured using the stable DPPH (2,2-diphenyl-1-picrylhydrazyl) radical, superoxide anion radical (pyrogallol autoxidation), and hydroxyl radical (Fenton reaction), according to the method of Blois 1958 [44], Xu et al. 2013 [45], and Harminder et al. 2010 [46], respectively. Every method was used with a slight modification. The essential oil solutions were diluted to different concentrations $(0.05,0.1,0.5,1,2,4,6,8,10$, and $20 \mathrm{mg} / \mathrm{mL}$ ) by petroleum ether. VC (Vitamin C) and VE (Vitamin E) were used as standards and were subjected to the same procedure for comparison. The capability to scavenge the free radical was 
calculated using the following equation: $(\%)=\left[A_{0}-\left(A_{i}-A_{s}\right)\right] / A_{0} \times 100$, where $A_{0}$ was the absorbance value of the blank, $A_{i}$ was the absorbance in the presence of the sample and the free radical, and $A_{S}$ was the absorbance of the sample without free radical. All determinations were done in triplicate and the concentration of essential oils that reduced the absorption of free radical solution by $50 \%\left(\mathrm{EC}_{50}\right)$ was obtained from a linear regression analysis.

Briefly, a solution of DPPH in ethanol was prepared and this solution $(100.0 \mu \mathrm{L})$ was added to $100.0 \mu \mathrm{L}$ of essential oil solutions at different concentrations. The mixture was shaken and left to stand for $30 \mathrm{~min}$ in the dark at room temperature, and then we measured the absorbance at $517 \mathrm{~nm}$ [47].

Three milliliters of Tris-HCL buffer solution ( $\mathrm{pH}$ 8.2) were incubated in a water bath at $25^{\circ} \mathrm{C}$ for $20 \mathrm{~min}$, and this solution was added to $2.0 \mathrm{~mL}$ of essential oil solutions at different concentrations. One milliliter of pyrogallol solution $(70 \mathrm{mM})$ was added to the mixture. Absorbance measurements were made at $420 \mathrm{~nm}$ after $4 \mathrm{~min}$ of reaction at room temperature.

The reaction mixture contained $1.0 \mathrm{~mL}$ ferrous sulfate solution $(10 \mathrm{mM}), 1.5 \mathrm{~mL}$ hydrogen peroxide $(10 \% w / v)$ solution, and various concentrations of essential oils. After mixing and standing for $10 \mathrm{~min}$, the reaction mixture was added to $2.0 \mathrm{~mL}$ salicylic acid $(10 \mathrm{mM})$ solution and then left to stand for $30 \mathrm{~min}$. The absorbance was measured at $510 \mathrm{~nm}$ against an appropriate blank solution and all experiments were performed in triplicate.

\subsection{Reducing Power Assay}

The reducing power of essential oils was determined by the method of Oyaizu 1986 [48], with minor modifications. An aliquot of essential oils at various concentrations $(0.05,0.1,0.5,1,2,4,6,8$, 10 , and $20 \mathrm{mg} / \mathrm{mL})$ was mixed with $2.5 \mathrm{~mL}$ potassium ferricyanide $(1 \% \mathrm{w} / \mathrm{v})$ solution and $2.5 \mathrm{~mL}$ phosphate buffer (0.2 M, pH 6.6). The mixture was incubated in a water bath at $50{ }^{\circ} \mathrm{C}$ for $20 \mathrm{~min}$, cooled, and then added to $2.5 \mathrm{~mL}$ trichloroacetic acid $(10 \% w / v)$. The mixture was centrifuged at $3000 \mathrm{rpm}$ for $10 \mathrm{~min}$. The supernatant $(2.5 \mathrm{~mL})$ was mixed with $2.0 \mathrm{~mL}$ distilled water and $0.5 \mathrm{~mL}$ $(0.1 \%)$ anhydrous iron (III) chloride $\left(\mathrm{FeCl}_{3}\right)$, and the absorbance was measured at $700 \mathrm{~nm}$ using an appropriate blank. VC and VE were used as references. Assays were carried out in triplicate and higher absorbance values indicated stronger reducing power.

\subsection{Statistical Analysis}

The concentrations (\%) of chemical constituents in essential oils were used to examine the relationship among four species of Schisandra. The antioxidant tests were conducted in triplicate and the results were expressed as mean \pm standard deviation (SD). The contents of chemical groups were selected as the clustering variables.

\section{Conclusions}

In this work, we investigated the chemical components and antioxidant activities of the essential oils in four species of Schisandra through GC-MS and antioxidant assay. It is clear that the essential oils of all samples are mainly composed of sesquiterpenes and oxygenated sesquiterpenes, which have good biological activity. Moreover, there are obvious differences between the kinds and contents of essential oils from the fruits of four species. Meanwhile, the antioxidant activity of the essential oils is affected by the bioactive composition. The results of our study could be considered the first to provide a direct comparison of the chemical components of the essential oils for these important traditional medicines, and could provide data for the further exploitation of Schisandra species.

Supplementary Materials: The following are available online, Table S1: Factors and levels for orthogonal test, Table S2: Results of L9 (34) orthogonal test, Table S3: The table of variance analysis, Table S4: Chemical compounds identified in the volatile oils of four species in Schisandra.

Author Contributions: X.W. and W.G. designed, guided, and participated in performing the experiments. Y.L., N.W. and Y.N. provided the plant material. X.W. analyzed the data. All co-authors discussed results, reviewed and corrected the manuscript. 
Acknowledgments: This work was supported by the National Natural Science Foundation of China (Grant No. 31070293); the National Eleventh-Five Year Science and Technology Support Program from Ministry of Science and Technology of the People's Republic of China (No. 2006BAI06A13-06); the Research and Development Program of Science and Technology of Shaanxi Province (No. 2014K-01-02), and the Fundamental Research Funds for the Central Universities (No. 2017TS035).

Conflicts of Interest: No potential conflict of interest was reported by the authors.

\section{References}

1. Editorial Committee of Flora of China. Flora of China; Science Press: Beijing, China, 1996; pp. $258-260$.

2. Saunders, R.M.K. Monograph of Schisandra (Schisandraceae). Syst. Bot. Monogr. 2000, 58, 1-146. [CrossRef]

3. Smith, A.C. The families Illiciaceae and Schisandraceae. Sargentia 1947, 7, 1-244.

4. Szopa, A.; Ekiert, R.; Ekiert, H. Current knowledge of Schisandra chinensis (Turcz.) Baill. (Chinese magnolia vine) as a medicinal plant species: A review on the bioactive components, pharmacological properties, analytical and biotechnological studies. Phytochem. Rev. 2017, 16, 195-218. [CrossRef] [PubMed]

5. The State Pharmacopoeia Commission of P. R. China. Pharmacopoeia of the People's Republic of China; China Medical Science Press: Beijing, China, 2015; p. 244. ISBN 9787506773379.

6. Guo, Y.L.; Wei, H.Y.; Lu, C.Y.; Gao, B.; Gu, W. Predictions of potential geographical distribution and quality of Schisandra sphenanthera under climate change. PeerJ 2016, 4, e2554. [CrossRef] [PubMed]

7. Lu, C.Y.; Gu, W.; Dai, A.H.; Wei, H.Y. Assessing habitat suitability based on geographic information system (GIS) and fuzzy: A case study of Schisandra sphenanthera Rehd. et Wils. in Qinling Mountains, China. Ecol. Model. 2012, 242, 105-115. [CrossRef]

8. Zhang, W.; Xu, M.; Liu, X.X.; Gu, W. Investigation of wild plant resources of Schisandra in Qinling Mountains. J. Plant Genet. Resour. 2014, 15, 236-241. [CrossRef]

9. Li, X.N.; Pu, J.X.; Du, X.; Yang, L.M.; An, H.M.; Lei, C.; He, F.; Luo, X.; Zheng, Y.T.; Lu, Y.; et al. Lignans with anti-HIV activity from Schisandra propinqua var. sinensis. J. Nat. Prod. 2009, 72, 1133-1141. [CrossRef] [PubMed]

10. Mu, H.X.; Li, X.S.; Fan, P.; Yang, G.Y.; Pu, J.X.; Sun, H.D.; Hu, Q.F.; Xiao, W.L. Dibenzocyclooctadiene lignans from the fruits of Schisandra rubriflora and their anti-HIV-1 activities. J. Asian Nat. Prod. Res. 2011, 13, 393-399. [CrossRef] [PubMed]

11. Xiao, W.L.; Gong, Y.Q.; Wang, R.R.; Weng, Z.Y.; Luo, X.; Li, X.N.; Yang, G.Y.; He, F.; Pu, J.X.; Yang, L.M.; et al. Bioactive nortriterpenoids from Schisandra grandiflora. J. Nat. Prod. 2009, 72, 1678-1681. [CrossRef] [PubMed]

12. Gu, W.; Wei, N.Y.; Wang, Z.Z. LC analysis of lignans from Schisandra sphenanthera Rehd. et Wils. Chromatographia 2008, 67, 979-983. [CrossRef]

13. Liu, X.X.; Liu, F.; Gu, W. Determination of lignans in four fruits of Schisandra genus in Qinling Mountains. J. Chin. Med. Mater. 2013, 36, 1053-1055. [CrossRef]

14. Regnault-Roger, C.; Vincent, C.; Arnason, J.T. Essential oils in insect control: Low-risk products in a high-stakes world. Annu. Rev. Entomol. 2012, 57, 405-424. [CrossRef] [PubMed]

15. Donato, R.; Santomauro, F.; Bilia, A.R.; Flamini, G.; Sacco, C. Antibacterial activity of Tuscan Artemisia annua essential oil and its major components against some foodborne pathogens. LWT_Food Sci. Technol. 2015, 64, 1251-1254. [CrossRef]

16. Venkanna, A.; Siva, B.; Poornima, B.; Vadaparthi, P.R.R.; Prasad, K.R.; Reddy, K.A.; Reddy, G.B.P.; Babu, K.S. Phytochemical investigation of sesquiterpenes from the fruits of Schisandra chinensis and their cytotoxic activity. Fitoterapia 2014, 95, 102-108. [CrossRef] [PubMed]

17. Kunihiro, K.; Myoda, T.; Tajima, N.; Gotoh, K.; Kaneshima, T.; Someya, T.; Toeda, K.; Fujimori, T.; Nishizawa, M. Volatile Components of the Essential Oil of Artemisia montana and Their Sedative Effects. J. Oleo Sci. 2017, 66, 843-849. [CrossRef] [PubMed]

18. Song, L.; Ding, J.Y.; Tang, C.; Yin, C.H. Compositions and biological activities of essential oils of Kadsura longepedunculata and Schisandra sphenanthera. Am. J. Chin. Med. 2007, 35, 353-364. [CrossRef] [PubMed]

19. Russo, A.; Formisano, C.; Rigano, D.; Cardile, V.; Arnold, N.A.; Senatore, F. Comparative phytochemical profile and antiproliferative activity on human melanoma cells of essential oils of three lebanese Salvia species. Ind. Crops Prod. 2016, 83, 492-499. [CrossRef] 
20. Baranauskienè, R.; Venskutonis, P.R.; Dambrauskienè, E.; Viškelis, P. Harvesting time influences the yield and oil composition of Origanum vulgare L. ssp. vulgare and ssp. hirtum. Ind. Crops Prod. 2013, 49, 43-51. [CrossRef]

21. Boukhris, M.; Hadrich, F.; Chtourou, H.; Dhouib, A.; Bouaziz, M.; Sayadi, S. Chemical composition, biological activities and DNA damage protective effect of Pelargonium graveolens L'Hér. essential oils at different phenological stages. Ind. Crops Prod. 2015, 74, 600-606. [CrossRef]

22. Samejo, M.Q.; Memon, S.; Bhanger, M.I.; Khan, K.M. Essential oils constituents in fruit and stem of Calligonum polygonoides. Ind. Crops Prod. 2013, 45, 293-295. [CrossRef]

23. Asakawa, Y.; Tomiyama, K.; Sakurai, K.; Kawakami, Y.; Yaguchi, Y. Volatile Compounds from the Different Organs of Houttuynia cordata and Litsea cubeba (L. citriodora). J. Oleo Sci. 2017, 66, 889-895. [CrossRef] [PubMed]

24. Stefanaki, A.; Cook, C.M.; Lanaras, T.; Kokkini, S. The Oregano plants of Chios Island (Greece): Essential oils of Origanum onites L. growing wild in different habitats. Ind. Crops Prod. 2016, 82, 107-113. [CrossRef]

25. Zhao, L.Q. Advanced research on terpenoids in Schisandra and their biological activity. Lishizhen Med. Mater. Med. Res. 2008, 19, 228-230. [CrossRef]

26. Li, X.; Nie, J.; Gao, Z.D.; Li, Z.G.; Deng, F.T.; Wu, X.W. Analysis of volatile oils from fruits of Schisandra chinensis (Turcz.) Baill. and Schisandra sphenanthera Rehd. et Wils. by ultrasonic-microwave assisted steam distillation coupled with gas chromatography-mass spectrometry. Food Sci. 2014, 35, 269-274. [CrossRef]

27. Ma, C.H.; Yang, L.; Zu, Y.G.; Liu, T.T. Optimization of conditions of solvent-free microwave extraction and study on antioxidant capacity of essential oil from Schisandra chinensis (Turcz.) Baill. Food Chem. 2012, 134, 2532-2539. [CrossRef] [PubMed]

28. Li, Q.F.; Lou, F.M.; Zhang, Q.R.; Duan, X.L.; Li, M.M. Analysis of essential oil from root and stem of Schisandra propinqua (Wall.) Bail. var. sinensis Oliv. with GC-MS. Fine Chem. 2010, 27, 138-141. [CrossRef]

29. Fan, Q.Y.; Dong, Z.J.; Li, Z.H.; Yin, X.; Yang, X.Y.; Feng, T.; Wei, K.; Liu, J.K.; Zhao, B.H. Two new ylangene-type sesquiterpenoids from cultures of the fungus Postia sp. J. Asian Nat. Prod. Res. 2014, 16, 254-258. [CrossRef] [PubMed]

30. Sabulal, B.; Dan, M.; John, J.A.; Kurup, R.; Pradeep, N.S.; Valsamma, R.K.; George, V. Caryophyllene-rich rhizome oil of Zingiber nimmonii from South India: Chemical characterization and antimicrobial activity. Phytochemistry 2006, 67, 2469-2473. [CrossRef] [PubMed]

31. Wu, Y.; Guo, S.S.; Huang, D.Y.; Wang, C.F.; Wei, J.Y.; Li, Z.H.; Sun, J.S.; Bai, J.F.; Tian, Z.F.; Wang, P.J.; et al. Contact and Repellant Activities of Zerumbone and Its Analogues from the Essential Oil of Zingiber zerumbet (L.) Smith against Lasioderma serricorne. J. Oleo Sci. 2017, 66, 399-405. [CrossRef] [PubMed]

32. Bhatia, S.P.; Letizia, C.S.; Api, A.M. Fragrance material review on elemol. Food Chem. Toxicol. 2008, 46, S147-S148. [CrossRef] [PubMed]

33. Paksoy, M.Y.; Diraz, E.; Diğrak, M.; Tutar, E.; Karaman, Ş. Essential oil composition and antimicrobial activity of two endemic Kundmannia SCOP. species from Turkey. Ind. Crops Prod. 2016, 79, 39-46. [CrossRef]

34. Khani, A.; Heydarian, M. Fumigant and repellent properties of sesquiterpene-rich essential oil from Teucrium polium subsp. capitatum (L.). Asian Pac. J. Trop. Med. 2014, 7, 956-961. [CrossRef]

35. Bhatia, S.P.; McGinty, D.; Letizia, C.S.; Api, A.M. Fragrance material review on cedrenol. Food Chem. Toxicol. 2008, 46, S97-S99. [CrossRef] [PubMed]

36. Wang, Y.H.; Essenberg, M. Inhibitor and substrate activities of sesquiterpene olefins toward (+)- $\delta$-cadinene-8-hydroxylase, a cytochrome P450 monooxygenase (CYP706B1). Phytochemistry 2010, 71, 1825-1831. [CrossRef] [PubMed]

37. Liu, Y.; Yang, M.H.; Wang, X.B.; Li, T.X.; Kong, L.Y. Caryophyllene sesquiterpenoids from the endophytic fungus, Pestalotiopsis sp. Fitoterapia 2016, 109, 119-124. [CrossRef] [PubMed]

38. Ud-Daula, A.F.M.S.; Demirci, F.; Salim, K.A.; Demirci, B.; Lim, L.B.L.; Baser, K.H.C.; Ahmad, N. Chemical composition, antioxidant and antimicrobial activities of essential oils from leaves, aerial stems, basal stems, and rhizomes of Etlingera fimbriobracteata (K.Schum.) R.M.Sm. Ind. Crops Prod. 2016, 84, 189-198. [CrossRef]

39. Feng, X.F.; Jing, N.; Li, Z.G.; Wei, D.; Lee, M.R. Ultrasound-Microwave Hybrid-Assisted Extraction Coupled to Headspace Solid-Phase Microextraction for Fast Analysis of Essential Oil in Dry Traditional Chinese Medicine by GC-MS. Chromatographia 2014, 77, 619-628. [CrossRef] 
40. Fan, S.P.; Chang, J.; Zong, Y.F.; Hu, G.S.; Jia, J.M. GC-MS Analysis of the Composition of the Essential Oil from Dendranthema indicum Var. Aromaticum Using Three Extraction Methods and Two Columns. Molecules 2018, 23, 576. [CrossRef]

41. Wang, Y.G.; Li, X.R.; Jiang, Q.J.; Sun, H.N.; Jiang, J.F.; Chen, S.M.; Guan, Z.Y.; Fang, W.M.; Chen, F.D. GC-MS Analysis of the Volatile Constituents in the Leaves of 14 Compositae Plants. Molecules 2018, 23, 166. [CrossRef] [PubMed]

42. Zhao, J.L.; Jiang, L.; Tang, X.H.; Peng, L.X.; Li, X.; Zhao, G.; Zhong, L.Y. Chemical Composition, Antimicrobial and Antioxidant Activities of the Flower Volatile Oils of Fagopyrum esculentum, Fagopyrum tataricum and Fagopyrum Cymosum. Molecules 2018, 23, 182. [CrossRef] [PubMed]

43. Tajabadi, F.; Khalighi-Sigaroodi, F.; Rezazadeh, S. Improving Gas Chromatography-Mass Spectrometry Analysis of Essential Oils by Multivariate Curve Resolution: Full Identification of Co-eluting Compounds of Dracocephalum moldavica L. Chromatographia 2017, 80, 1069-1077. [CrossRef]

44. Biois, M.S. Antioxidant determinations by the use of a stable free radical. Nature 1958, 181, 1199-1200. [CrossRef]

45. Xu, C.; Liu, S.; Liu, Z.Q.; Song, F.R.; Liu, S.Y. Superoxide generated by pyrogallol reduces highly water-soluble tetrazolium salt to produce a soluble formazan: A simple assay for measuring superoxide anion radical scavenging activities of biological and abiological samples. Anal. Chim. Acta 2013, 793, 53-60. [CrossRef] [PubMed]

46. Singh, H.P.; Kaur, S.; Mittal, S.; Batish, D.R.; Kohli, R.K. In vitro screening of essential oil from young and mature leaves of Artemisia scoparia compared to its major constituents for free radical scavenging activity. Food Chem. Toxicol. 2010, 48, 1040-1044. [CrossRef] [PubMed]

47. Fitsiou, E.; Mitropoulou, G.; Spyridopoulou, K.; Vamvakias, M.; Bardouki, H.; Galanis, A.; Chlichlia, K.; Kourkoutas, Y.; Panayiotidis, M.I.; Pappa, A. Chemical Composition and Evaluation of the Biological Properties of the Essential Oil of the Dietary Phytochemical Lippia citriodora. Molecules 2018, $23,123$. [CrossRef] [PubMed]

48. Oyaizu, M. Studies on products of browning reaction: Antioxidative activity of products of browning reaction prepared from glucosamine. Jpn. J. Nutr. Diet. 1986, 44, 307-315. [CrossRef]

Sample Availability: Samples of the compounds are available from the authors.

(c) 2018 by the authors. Licensee MDPI, Basel, Switzerland. This article is an open access article distributed under the terms and conditions of the Creative Commons Attribution (CC BY) license (http:// creativecommons.org/licenses/by/4.0/). 